\title{
Effects of Oxygen and Carbon Dioxide on Inosine Fermentation ${ }^{\dagger}$
}

\author{
Hiroshiro ShibaI, Ayaaki Ishizaki, Hiroshi Mizuno \\ and Yoshio Hirose \\ Central Research Laboratories of Ajinomoto Co., Inc., Kawasaki, Japan \\ Received June 24, 1972
}

\begin{abstract}
The effects of oxygen and carbon dioxide in inosine fermentation were investigated from the industrial viewpoint. Oxygen supply at the rate of more than $5 \times 10^{-7} \mathrm{~mole} / \mathrm{ml} \cdot \mathrm{min}$ was indispensable for maintaining the high productivity of inosine in jar fermentors as well as in shaking flasks. Oxygen deficiency due to insufficient oxygen supply, on the other hand, resulted in the inhibition of inosine production, even though glucose added to the medium was entirely assimilated. In addition to sufficient oxygen supply ventilation was also indispensable since an increased tension of carbon dioxide reduced the inosine-producing capability of the cells.
\end{abstract}

Inosinic acid has become one of the popular flavor-enhancing materials. In our laboratories, an industrial process of the production of inosinic acid has been investigated and developed. Inosine, a key substance in this process, is microbially produced ${ }^{13}$ and then chemically phosphorylated to form inosinic acid. ${ }^{2}$ The microbial production of inosine, combined with the synthetic technique of organic chemistry, is now an important branch of the fermentation industry in Japan.

Since the biosynthesis of inosine from glucose requires much energy, ${ }^{3)}$ sufficient oxygen must be supplied to fermentation broth in order to make the cells accumulate a large amount of inosine. Therefore, studies on aeration were essential in this fermentation." Many studies have been reported on genetical derivations of inosine-producing mu$\operatorname{tants}^{5,6)}$ and their cultural conditions suitable for inosine accumulation, but very few studies have been made from the industrial viewpoint. ${ }^{4}$

This paper refers to the effects of oxygen and carbon dioxide on inosine production, showing an inhibitory effect of carbon dioxide

\footnotetext{
+ Studies on Oxygen Transfer in Submerged Fermentation. Part X.

This paper was presented at the Annual Meeting of Agricultural Chemical Society of Japan held in Tokyo on April 1, 1969 and at the Meeting of Agricultural Chemical Society of Japan held in Tokyo on June 27 , 1970.
}

on inosine production and a remarkable effect of ventilation to reduce the inhibition.

\section{MATERIALS AND METHODS}

Microorganism. The organism used was a mutant derived from Bacillus subtilis $\mathrm{K}$ and had a potent ability to accumulate inosine.

Culture method. Seed culture was carried out in a liquid medium for $12 \mathrm{hr}$ at $34^{\circ} \mathrm{C}$, then it was transferred into the main culture at the ratio of $5 \%$ to the fermentation medium. Fermentation was carried out for $60 \mathrm{hr}$ at $34^{\circ} \mathrm{C}$. The $\mathrm{pH}$ of the medium was maintained at approximately 6.0 with $\mathrm{CaCO}_{3}$ for shaking cultures, and at 6.5 with gaseous ammonia for the cultures in 36 liter jar fermentors.

The medium for seed culture was composed of $6 \%$ glucose, $0.5 \%$ RNA (purity $80 \%$ ), $4 \%$ Aji-eki (soy bean hydrolyzate, $2.42 \%$ nitrogen was contained), $0.3 \% \mathrm{NH}_{4} \mathrm{Cl}, 0.1 \% \mathrm{KH}_{2} \mathrm{PO}_{4}, 0.04 \% \quad \mathrm{MgSO}_{4} \cdot 7 \mathrm{H}_{2} \mathrm{O}$, $0.001 \% \mathrm{FeSO}_{4} \cdot 7 \mathrm{H}_{2} \mathrm{O}$ and $0.001 \% \quad \mathrm{MnSO}_{4} \cdot 5 \mathrm{H}_{2} \mathrm{O}$. The fermentation medium for shaking culture was composed of $8 \%$ glucose, $0.08 \%$ RNA, $4 \%$ Aji-eki, $0.03 \%$ DL-methionine, $2.1 \% \mathrm{KCl}, 0.05 \% \quad \mathrm{KH}_{2} \mathrm{PO}_{4}$, $0.04 \% \mathrm{MgSO}_{4} \cdot 7 \mathrm{H}_{2} \mathrm{O}, 0.001 \% \mathrm{FeSO}_{4} \cdot 7 \mathrm{H}_{2} \mathrm{O}, 0.001 \%$ $\mathrm{MnSO}_{4} \cdot 5 \mathrm{H}_{3} \mathrm{O}$ and $2 \% \mathrm{CaCO}_{3}$. The fermentation medium for culture in 36 liter jar fermentors was composed of $8 \%$ glucose, $0.08 \%$ RNA, $4 \%$ Aji-eki, $0.03 \%$ DL-methionine, $2.1 \% \mathrm{KCl}, 0.05 \% \mathrm{KH}_{2} \mathrm{PO}_{4}$, $0.04 \% \quad \mathrm{MgSO}_{4} \cdot 7 \mathrm{H}_{2} \mathrm{O}, \quad 0.001 \% \quad \mathrm{FeSO}_{4} \cdot 7 \mathrm{H}_{2} \mathrm{O}$ and $0.001 \% \mathrm{MnSO}_{4} \cdot 5 \mathrm{H}_{2} \mathrm{O}$.

Oxygen supply. In order to study the influence of oxygen supply on inosine productivity, the volume of the medium in a $500 \mathrm{ml}$ flask was varied between $20 \mathrm{ml}$ 
and $300 \mathrm{ml}$. The rates of oxygen supply in shaking cultures were also varied using the apparatus shown in Fig. 1. Air was supplied to the flask through the filter made from polyvinylalcohol. The rate of air flow was controlled by regulating the valve attached to the flow meter. In jar-fermentor cultures, the condition of oxygen supply was controlled by changing the rate of air flow and agitation speed. A mixed gas of air and oxygen, air and carbon dioxide, or air and nitrogen was introduced to the fermentation vessel at a constant flow rate using the apparatus shown in Fig. 2 in order to investigate the effects of oxygen and carbon dioxide in inosine fermentation.

Analysis. For the determination of inosine, fermentation broths were applied to ascending paper chromatography using a mixture of n-propanol, $\mathrm{NH}_{4} \mathrm{OH}$ and water (20:15:13 by volume), followed by elution with $0.01 \mathrm{~N} \mathrm{HCl}$ and spectrophotometrical measurement of the ultraviolet-absorbing spots.

Glucose in the medium was determined by the manometric method using glucose oxidase.

Cell growth was expressed by the weight of dry

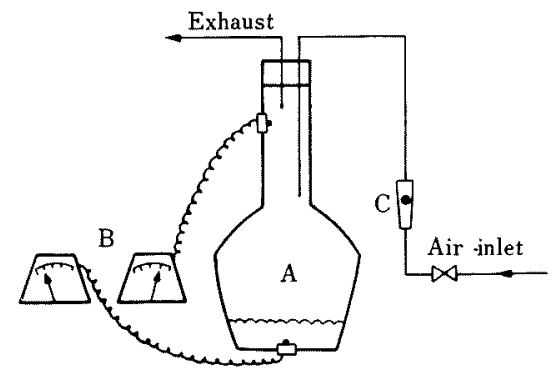

FIG 1. An Apparatus for the Study on Oxygen Transfer in Shaken Cultures.

A; shaking flask, B; oxygen analyzer, C; flow meter.

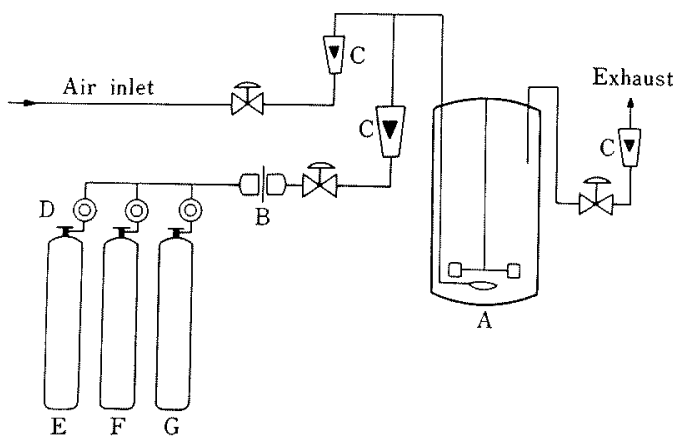

FIG. 2. Flow Diagram for Fermentation Using a Mixed Gas of Air and Oxygen, Air and Carbon Dioxide, or Air and Nitrogen.

A; fermentor, B; air filter, C; flow meter, D; pressure reducing valve, $\mathrm{E}$; liquid oxygen, $\mathrm{F}$; liquid carbon dioxide, $\mathrm{G}$; liquid nitrogen. cells.

The partial pressures of oxygen in the gas phase and in the liquid phase were determined using a Bechman Model 777 Oxygen Analyzer, and that of carbon dioxide in the gas phase using the apparatus of Fuji Electric Co. The rates of oxygen transfer in biological systems were measured with the method already reported in our previous paper. ${ }^{71}$

\section{RESULTS}

Effect of dissolved oxygen level on cell's respiration

Figure 3 shows the relationship between the respiration rate of cells and the dissolved oxygen $\left(P_{L}\right.$, atm) level. The respiration rate of fermentation broth containing $5.5 \mathrm{mg} / \mathrm{ml}$ of cells was observed as the values between $5.5 \times 10^{-7}$ and $6.5 \times 10^{-7} \mathrm{~mole} / \mathrm{ml} \cdot \mathrm{min}$ when the dissolved oxygen level was maintained above $0.01 \mathrm{~atm}$. The respiration rate was less than $5.5 \times 10^{-7} \mathrm{~mole} / \mathrm{ml} \cdot \mathrm{min}$ when the dissolved oxygen level was zero as measured

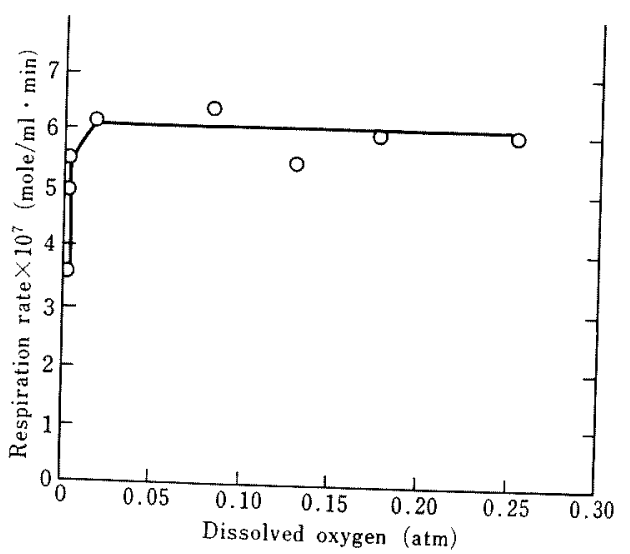

FIG. 3. Effect of the Dissolved Oxygen Level on Cell's Respiration.

Fermentation broth containing $5.5 \mathrm{mg} / \mathrm{ml}$ of cells was applied for this experiment in jar fermentors.

by membrane-coated oxygen electrodes. These results indicate that the oxygen demand of cells was satisfied at the dissolved oxygen level above 0.01 atm. Cell's respiration proceeded at a constant rate so long as dissolved oxygen was above the critical value for respiration $\left(P_{\mathrm{L} \text { erit }}, \mathrm{atm}\right)$, which was not more than $0.01 \mathrm{~atm}$. 
Typical time course of inosine fermentation

An example of the time course of this fermentation is presented in Fig. 4. The condition of oxygen supply was as follows; agitation speed was $250 \mathrm{rpm}$ and air flow rate,
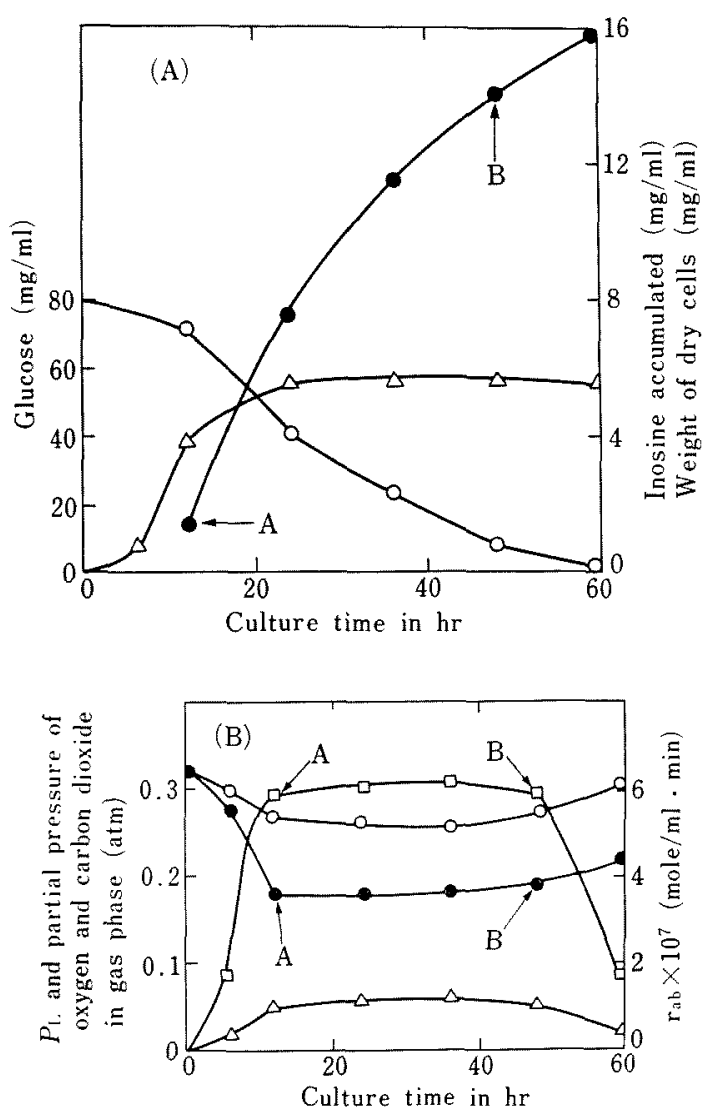

FIg. 4. Typical Time Course Curves for Inosine Fermentation.

(A); glucose $(\mathrm{O}-\mathrm{O})$, inosine $(-\bullet)$, weight of dry cells $(\Delta-\Delta)$

(B); partial pressure of carbon dioxide in gas phase $(\triangle-\triangle)$, partial pressure of oxygen in gas phase $(\bigcirc-0), P_{L}(-\bullet), r_{a b}(\square-\square)$

20 liter $/ \mathrm{min}$. This condition resulted in the maintenance of the dissolved oxygen level above $0.17 \mathrm{~atm}$ throughout the fermentation. The respiratory quotient was approximately 1 , since the average rate of oxygen absorption was $4.6 \times 10^{-7} \mathrm{~mole} / \mathrm{ml} \cdot \mathrm{min}$, which was equal to that of carbon dioxide evolution. The cell growth reached its stationary phase within first $24 \mathrm{hr}$. Inosine accumulation began at the logarithmic phase of the cell growth and continued until the end of the fermentation when glucose supplied in the medium was completely consumed.

Relationship between inosine accumulation and rate of oxygen transfer

The cells produced approximately $80 \%$ of excreted inosine during the period between the points $\mathrm{A}$ and $\mathrm{B}$ in Fig. 4, and the rate of oxygen transfer $\left(\mathbf{r}_{\mathrm{a} b}, \mathrm{~mole} / \mathrm{ml} \cdot \mathrm{min}\right)$ as well as $P_{\mathrm{L}}$ was nearly constant during that period were reasonably available as key indices for the study of the relationship between inosine accumulation and oxygen supply. Figure 5

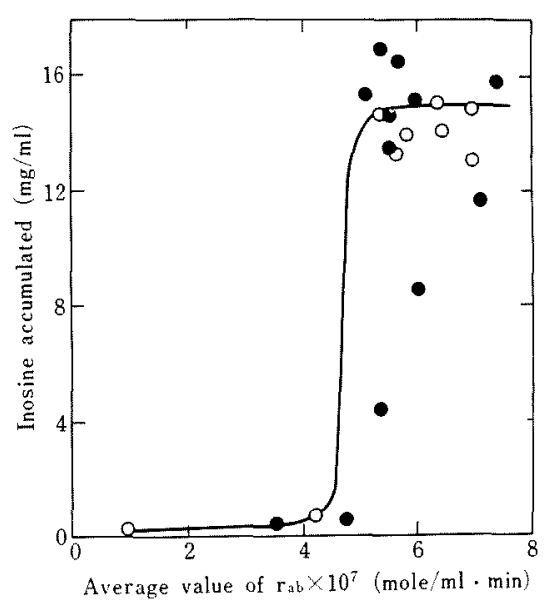

FIG. 5. Relationship between Inosine Accumulation and Average Value of rab.

The experiments were carried out in shaking flasks $(\mathrm{O}-\mathrm{O})$ and in jar-fermentors

shows that inosine accumulation was completely inhibited under the condition of insufficient oxygen supply, where respiration rate was less than $5 \times 10^{-7} \mathrm{~mole} / \mathrm{ml} \cdot \mathrm{min}$. At the respiration rate more than $5 \times 10^{-7}$ mole/ $\mathrm{ml} \cdot \mathrm{min}$, on the other hand, the cells produced a large amount of inosine. Among the data obtained in jar fermentor cultures, however, some exceptions were observed in that inosine accumulation was considerably inhibited even under sufficient oxygen supply. These results indicate that not only oxygen supply but also some other cultural conditions should be taken 
into account in order to attain the high productivity of inosine.

Relationship between inosine accumulation and dissolved oxygen level

The influence of the dissolved oxygen level on inosine accumulation was investigated in shaking cultures (Fig. 6) and in jar-fermentor cultures (Fig. 7). As shown in these figures, inosine accumulation decreased under the

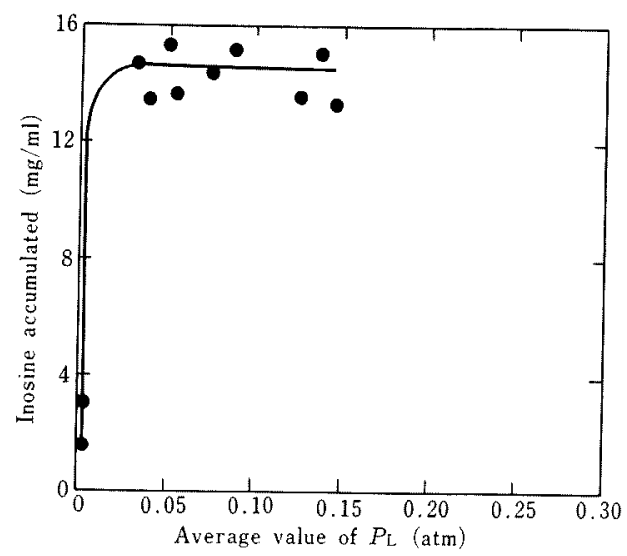

FIG, 6. Relationship between Inosine Accumulation and the Average Value of $P_{\mathrm{L}}$ in Shaken Cultures.

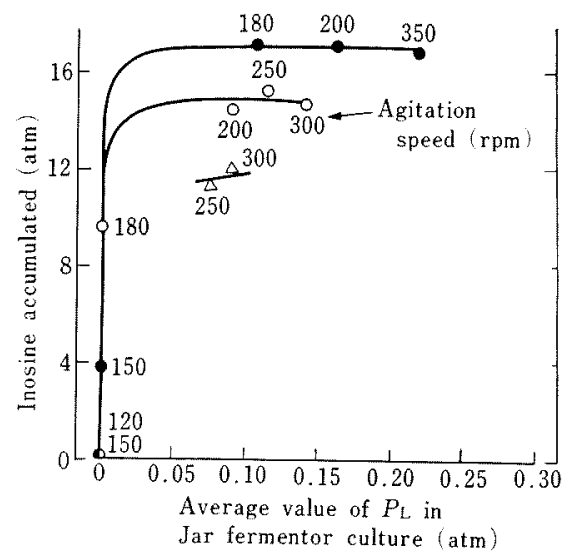

FIG. 7. Relationship between Inosine Accumulation and the Average Value of $P_{\mathrm{L}}$ in Jar-fermentor Cultures.

The average value of $P_{\mathrm{L}}$ was increased according to the increase in agitation speed; 250 and $300 \mathrm{rpm}$ at the rate of 6 liter/min of air flow $(\triangle-\Delta), 150,180,200$, 250 and $300 \mathrm{rpm}$ at the rate of 9 liter $/ \mathrm{min}$ of air flow $(\mathrm{O}-\mathrm{O})$, and $120,150,180,200$ and $350 \mathrm{rpm}$ at the rate of $30 \mathrm{liter} / \mathrm{min}$ of air flow (-) condition that the average value of $P_{L}$ was near zero as measured by membrane-coated oxygen electrodes. This inhibition was supposedly resulted from oxygen deficiency. The condition of oxygen supply to maintain the average value of $P_{\mathrm{L}}$ above 0.025 atm for shaking cultures and 0.075 atm for jar-fermentor cultures was sufficient for the cells to accumulate a large amount of inosine. The concentration of accumulated inosine, however, was confirmed to be varied between $11.2 \mathrm{mg} / \mathrm{ml}$ and $17.2 \mathrm{mg} / \mathrm{ml}$ in jar-fermentor cultures under sufficient oxygen supply. These results were analyzed by plotting the value of accumulated inosince against the average value of $P_{\mathrm{L}}$ for the parameter air flow rate. When the rate of air flow was 9 liter $/ \mathrm{min}$, inosine production was markedly inhibited because of oxygen deficiency at the agitation speed of 150 or $180 \mathrm{rpm}$, and the plateau of inosine accumulation was observed at the agitation speed more than $200 \mathrm{rpm}$. When the rate of air flow was increased to 30 liter/ min, the cells produced the largest amount of inosine at the agitation speed more than 180 rpm. This suggests that not only sufficient supply of oxygen but also the high flow rate of air was indispensable for the high productivity of inosine.

\section{Critical level of dissolved oxygen for inosine production}

From the viewpoint of the practical operation of this fermentation, it was important to know the critical level of dissolved oxygen for inosine production. Therefore, fermentation under the condition of the dissolved oxygen level lower than $0.025 \mathrm{~atm}$ was carried out in order to study the influence of the low dissolved oxygen level on inosine production. At the air-flow rate of $30 \mathrm{liter} / \mathrm{min}$, agitation speed was controlled so as to maintain the dissolved oxygen level slightly above zero as registered by a membrane electrode. As shown in Fig. 8, the low level of dissolved oxygen between $0.01 \mathrm{~atm}$ and $0.015 \mathrm{~atm}$ throughout the most part of the fermentation did not inhibit inosine accumulation. From this fact, the 

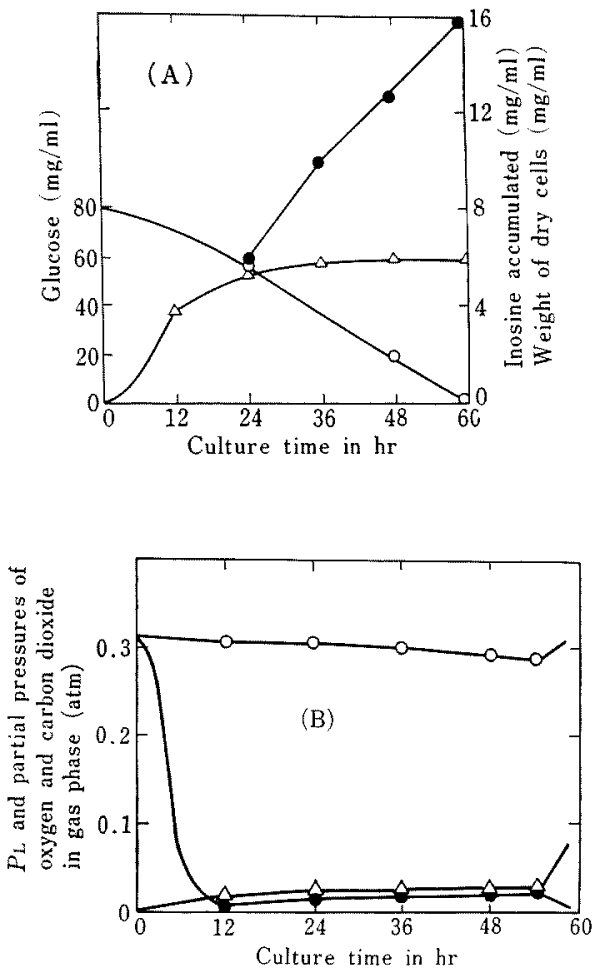

FIg. 8. Time Course Curves for Inosine Fermentation under an Extremely Low Dissolved Oxygen Level.

(A); glucose $(\mathrm{O}-\mathrm{O})$, inosine $(-)$, weight of dry cells $(\triangle-\triangle)$.

(B); partial pressure of gas-phase carbon dioxide $(\mathrm{O}-\mathrm{O})$, partial pressure of gas-phase oxygen $(\mathrm{O}-\mathrm{O}), P_{L}(\mathbf{0}-\mathbf{0})$

critical level of dissolved oxygen for inosine production was considered to be lower than $0.01 \mathrm{~atm}$. The membrane-coated oxygen electrode employed in our experiment did not precisely monitor the lower level of dissolved oxygen than $0.01 \mathrm{~atm}$. For the industrial purpose, however, the electrode could be employed to control the practical operation of this fermentation, assuming that the critical level of dissolved oxygen for inosine production is slightly above zero.

Effect of carbon dioxide tension on inosine production

The poor yield of inosine under the limited air flow rate in Fig. 7 was suggested to be the result of inadequate ventilation which caused a high partial pressure of gas-phase carbon dioxide in the culture system. The concentration of produced inosine is plotted against the partial pressure of gas-phase carbon dioxide in Fig. 9. Inosine accumulation was decreased as the partial pressure of gas-phase carbon dioxide was increased. This result indirectly indicates the inhibitory effect of carbon dioxide on inosine production.

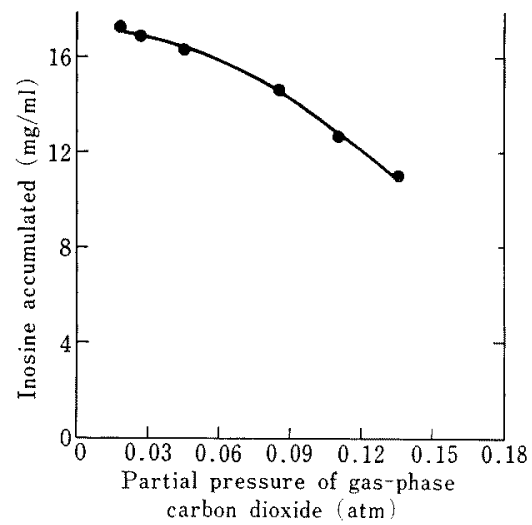

FIG. 9. Relationship between Inosine Accumulation and the Partial Pressure of Gas-phase Carbon Dioxide.

The experiments were carried out under the condition of sufficient oxygen supply $\left(P_{\mathrm{L}}>P_{\mathrm{L}}\right.$ crit $)$.

Inhibitory effect of carbon dioxide and effect of ventilation on product formation.

In order to clarify the inhibitory effect of carbon dioxide, some culture experiments were performed under a high partial pressure of carbon dioxide in which a mixed gas of air and carbon dioxide was employed for aeration. The suppressed accumulation of inosine observed at $0.135 \mathrm{~atm}$ of gas-phase carbon dioxide, as presented in the line 2 of Table I, suggests that high tension of carbon dioxide in the culture system was inhibitory to inosine production. This inhibition, however, was demonstrated to be recovered by introducing a mixed gas of air and nitrogen into the fermentor and lowering the partial pressure of carbon dioxide to $0.045 \mathrm{~atm}$ as shown in the line 3 of Table I.

Inosine accumulation under high oxygen tension It was examined whether the inhibition 
Table I. The Inhibitory Effect of Carbon Dioxide AND THE EFFECT OF VentILATION ON INOSINE PRODUCTION

\begin{tabular}{|c|c|c|c|c|c|c|}
\hline \multicolumn{3}{|c|}{$\begin{array}{c}\text { Composition of } \\
\text { supplied gas } \\
(1 / \mathrm{min})\end{array}$} & \multicolumn{2}{|c|}{$\begin{array}{l}\text { Average partial } \\
\text { pressure in } \\
\text { gas phase } \\
\text { (atm) }\end{array}$} & \multirow[t]{2}{*}{$\begin{array}{l}\text { Average } \\
\quad \text { of } \\
P_{\mathrm{L}}(\mathrm{atm})\end{array}$} & \multirow[t]{2}{*}{$\begin{array}{l}\text { Inosine } \\
\text { accumulat- } \\
\text { ed } \\
(\mathrm{mg} / \mathrm{ml})\end{array}$} \\
\hline air & $\mathrm{CO}_{2}$ & $\mathrm{~N}_{2}$ & $\mathrm{O}_{2}$ & $\mathrm{CO}_{2}$ & & \\
\hline 20 & & & 0.27 & 0.045 & 0.20 & 15 \\
\hline 20 & 2 & & 0.27 & 0.135 & 0.20 & 13.1 \\
\hline 6 & & 14 & 0.12 & 0.045 & 0.03 & 14.9 \\
\hline
\end{tabular}

caused by high tension of carbon dioxide was competitively recovered under high oxygen tension. The dissolved oxygen level was increased by aerating the liquid with a mixed gas of air and oxygen at the flow rate of 6 liter $/ \mathrm{min}$. The results of the fermentation under the high dissolved oxygen level are shown in Table II. The inhibition caused by high tension of carbon dioxide (Table I, line 1) was not recovered by increasing the dissolved oxygen level up to $0.45 \mathrm{~atm}$ (Table II, line 3 and 4), and cell's respiration proceeded at a constant rate irrespectively of such high oxygen tension.

\section{DISCUSSION}

As a measure of aeration effectiveness, the rate of oxygen transfer in the biological systems was adopted for the study of the influences of oxygen supply in inosine fermentation. The transfer rate to assure the high productivity of inosine was above $5 \times 10^{-7} \mathrm{~mole} / \mathrm{ml} \cdot \mathrm{min}$ in jar-fermentor cultures as well as in shaking cultures. This value was smaller than that observed in glutamic acid fermentation. ${ }^{8}$

Insufficient oxygen supply markedly inhibit- ed inosine accumulation, even though glucose in the medium was completely assimilated. This fact suggests that some other product might be excreted in place of inosine. In glutamic acid fermentation, the decrease of the rate of oxygen supply caused the change in the amount and the kind of the products." In this fermentation, the biosynthesis of inosine from glucose requires ATP yielded by energy metabolism, which is sensitive to oxygen deficiency. Therefore, some intermediate metabolite of glucose degradation was implied to be accumulated under insufficient oxygen supply. The identification of by-products is now under study in our laboratories.

The critical level of dissolved oxygen for glutamic acid production was reported to be extremely low. ${ }^{10}$ This was the same as the critical level for inosine production, which was lower than $0.01 \mathrm{~atm}$. For the investigation of the microbial response to an extremely low level of dissolved oxygen, the membranecoated oxygen electrode employed in our experiments was not perfect and some other method is required for future studies. It may bring about some significant information in this field to measure oxidation-reduction potentials or the ratio of the respiration rate at an extremely low level of dissolved oxygen to the maximum respiration rate under sufficient oxygen supply.

A few studies have been made concerning the ventilation effect in microbial cultures, ${ }^{11 \sim 18}$ ) in marked contrast to many investigations on oxygen supply. ${ }^{14,15}$, The inhibitory effect of carbon dioxide was remarkable in penicillin fermentation $^{11)}$ and slight in glutamic acid

Table II. Inosine Fermentation under High Oxygen Tension

Fermentation was carried out using a mixed gas of air and oxygen.

\begin{tabular}{|c|c|c|c|c|c|}
\hline \multirow[t]{2}{*}{$\begin{array}{l}\text { Flow rate } \\
(1 / \mathrm{min})\end{array}$} & \multicolumn{2}{|c|}{$\begin{array}{l}\text { Average partial } \\
\text { pressure in gas } \\
\text { phase (atm) }\end{array}$} & \multirow{2}{*}{$\begin{array}{l}\text { Average } \\
\text { of } \mathrm{P}_{\mathrm{L}} \\
\text { (atm) }\end{array}$} & \multirow{2}{*}{$\begin{array}{c}\text { Average of } \\
r_{a b} \times 10^{7} \\
(\mathrm{~mole} / \mathrm{ml} \cdot \mathrm{min})\end{array}$} & \multirow{2}{*}{$\begin{array}{c}\text { Inosine } \\
\text { accumulation } \\
(\mathrm{mg} / \mathrm{ml})\end{array}$} \\
\hline & $\mathrm{O}_{2}$ & $\mathrm{CO}_{2}$ & & & \\
\hline 6 & 0.18 & 0.135 & 0.03 & 6.62 & 10.7 \\
\hline 18 & 0.27 & 0.045 & 0.18 & 5.96 & 16.0 \\
\hline 6 & 0.27 & 0.135 & 0.25 & 5.96 & 11.7 \\
\hline 6 & 0.45 & 0.120 & 0.44 & 5.30 & 10.7 \\
\hline
\end{tabular}


fermentation. ${ }^{13}$ ) According to the results in our experiments on inosine fermentation, carbon dioxide was inhibitory to product formation, and ventilation had a remarkable effect to restore this inhibition. From this observation, the studies on ventilation in submerged fermentations were thought to be necessary and investigations on quantitative analysis and dynamic aspects of carbon dioxide in culture systems were made. ${ }^{16 \sim 18}$

In inosine fermentation, aeration and agitation were discussed from the following two standpoints; the maintenance of the dissolved oxygen value above the critical level for the cells to satisfy their oxygen demand and the assurance of adequate ventilation to eliminate carbon dioxide which is inhibitory to inosine production.

\section{REFERENCES}

1) R. Aoki, H. Momose, Y. Kondo, N. Muramatsu and Y. Tsuchiya, J. Gen. Appl. Microbiol., 9, 403 (1963).

2) M. Yoshikawa and T. Kato, Bull. Chem. Soc. Japan, 40, 2849 (1967).

3) B. Magasanik, "The Bacteria," Vol. III, ed. by
I. G. Gansalus and R. Y. Stainer, Academic Press Inc., New York, N. Y., 1960, p. 295.

4) R. Aoki, Y. Kondo, Y. Hirose and H. Okada, J. Gen. Appl. Microbiol., 14, 411 (1968).

5) R. Aoki, H. Momose, Y. Kondo, N. Muramatsu and Y. Tsuchiya, ibid., 9, 387 (1963).

6) K. Uchida, A. Kuninaka, H. Yoshino and $M$. Kibi, Agr. Biol. Chem., 25, 804 (1961).

7) Y. Hirose, S. Yamanaka, H. Okada and K. Kinoshita, ibid., 29, 989 (1965).

8) Y. Hirose, H. Sonoda K. Kinoshita and H. Okada, ibid., 30, 585 (1966).

9) H. Okada, I. Kameyama, S. Okumura and T. Tsunoda, J. Gen. Appl. Microbiol., 7, 177 (1961).

10) $Y$. Hirose, $H$. Sonoda, K. Kinoshita and $H$. Okada, Agr. Biol. Chem., 31, 1217 (1967).

11) J. B. Foster and J. B. Davis, Arch. Biochem., 21, 135 (1949).

12) L. Nyri and Z. L. Lengyel, Biotechnol. Bioeng., 7, 343 (1965).

13) Y. Hirose, H. Sonoda, K. Kinoshita and H. Okada, Agr. Biol. Chem., 32, 851 (1968).

14) R. K. Finn, Bact. Rev., 18, 254 (1954).

15) L. W. Richards, Progr. Ind. Microbiol, 3, 141 (1961).

16) A. Ishizaki, H. Shibai, Y. Hirose and T. Shiro, Agr. Biol. Chem., 35, 1733 (1971).

17) A. Ishizaki, Y. Hirose and T. Shiro, ibid., 35, 1852 (1971).

18) A. Ishizaki, Y. Hirose and T. Shiro, ibid., 35, 1860 (1971). 